\title{
Campanulaceae da Serra Negra, Minas Gerais, Brasil ${ }^{1}$
}

\author{
Campanulaceae of Serra Negra, Minas Gerais, Brazil ${ }^{1}$
}

Grécia de Andrade Souza ${ }^{2}$, Silvana Aparecida Pires de Godoy ${ }^{3,4}$ \& Fátima Regina Gonçalves Salimena ${ }^{2}$

\begin{abstract}
Resumo
Apresenta-se o estudo taxonômico da família Campanulaceae na Serra Negra, região com predomínio de campos rupestres e florestas de altitude, localizada no Sul da Zona da Mata de Minas Gerais, no Complexo da Serra da Mantiqueira. Foram registradas dez espécies incluídas em três gêneros: Centropogon cornutus, Lobelia exaltata, L. hilaireana, L. fistulosa, L. thapsoidea, Siphocampylus longipedunculatus, S. macropodus, S. nitidus, S. psilophyllus e Siphocampylus aff. fluminensis. São apresentadas chaves de identificação, descrições, ilustrações, comentários taxonômicos, ecológicos e de distribuição geográfica. Ressalta-se ainda a redescoberta de S. psilophyllus após 30 anos sem registros de coleta para a espécie, o que alertou para outras análises devido ao indicativo de ser uma espécie ameaçada, atualmente conhecida de apenas cinco localidades, em área de ocupação reduzida.
\end{abstract}

Palavras-chave: Campos rupestres, Floresta Atlântica, Serra da Mantiqueira.

\begin{abstract}
The taxonomic study of family Campanulaceae of Serra Negra is presented, a region where campos rupestres and montane forests predominate, located in the south of Zona da Mata of Minas Gerais, in the Serra da Mantiqueira mountain range. We recorded 10 species in three genera: Centropogon cornutus, Lobelia exaltata, L. hilaireana, L. fistulosa, L. thapsoidea, Siphocampylus aff. fluminensis, S. longipedunculatus, S. macropodus, S. nitidus, and S. psilophyllus. Identification keys, descriptions, illustrations, comments on taxonomic, ecological and geographic distribution are provided. It is worth noting the rediscovery of $S$. psilophyllus after 30 years without collection records for the species, which advised further analysis due to being indicative of an endangered species, currently known only in five locations in small patches.
\end{abstract}

Key words: "Campos rupestres", Atlantic Forest, Serra da Mantiqueira.

\section{Introdução}

A família Campanulaceae inclui 84 gêneros e 2.380 espécies com distribuição cosmopolita e de ocorrência nos mais variados habitats (Godoy 2003a; Lammers 2007; Stevens 2001 onwards). Apresenta sistema laticífero bem desenvolvido e formas de vida variadas, sendo notável a paquicaulia, desenvolvimento de caules eretos em plantas herbáceas, que chegam a quase $4 \mathrm{~m}$ de altura, característica de algumas espécies de Lobelioideae. As folhas são alternas, raro opostas ou verticiladas, simples, sem estípulas. As flores são bissexuadas, prefloração valvar, pentâmeras, actinomorfas ou zigomorfas, com hipanto, campanuladas ou tubulosas, ressupinadas em Lobelioideae, isoladas ou em inflorescências racemosas ou cimosas. Androceu isostêmone, estames alternos, livres ou monadelfos, sempre aderidos ao disco nectarífero ou à base da corola; anteras livres ou sinânteras, introrsas. Gineceu sincárpico, ovário ínfero, raro semi-ínfero, carpelos 2-3(-5), óvulos numerosos, anátropos, placentação axial. Fruto cápsula loculicida apical com lobos curtos, raro poricida, ou bacóide; sementes numerosas por lóculo, pequenas, aladas ou não.

\footnotetext{
${ }^{1}$ Monografia de Conclusão de Curso da primeira autora.

${ }^{2}$ Universidade Federal de Juiz de Fora, Inst. Ciências Biológicas, Depto. Botânica, Campus Universitário, São Pedro, 36036-900, Juiz de Fora, MG, Brasil.

${ }^{3}$ Universidade de São Paulo, Escola de Artes, Ciências e Humanidades, Av. Arlindo Bettio 1000, Ermelino Matarazzo, 03828-000, São Paulo, SP, Brasil.

${ }^{4}$ Autor para correspondência: sapgodoy@usp.br
} 
No Brasil a família está representada por 53 espécies, duas subespécies e uma variedade, sendo a maioria das espécies (37) de ocorrência restrita ao território brasileiro, principalmente em regiões serranas (Serra Geral, Serra do Mar, Serra da Mantiqueira, Serra da Bocaina, Cadeia do Espinhaço), nos domínios do Cerrado, Atlântico e das Caatingas, sendo frequentes nos campos rupestres de Goiás, Minas Gerais e Bahia (BGF 2015). Para o estado de Minas Gerais, são escassos os trabalhos sobre a família, sendo conhecidos apenas os trabalhos de Godoy $(1992 ; 2003 b)$ na Serra do Cipó e Grão-Mogol, respectivamente.

A Serra Negra pertence ao complexo da Serra da Mantiqueira, uma das maiores e mais importantes cadeias montanhosas da região sudeste do Brasil, compreendendo parte dos estados de São Paulo, Rio de Janeiro, Minas Gerais e Espírito Santo e que abriga cerca de $20 \%$ dos remanescentes da Mata Atlântica mineira (Costa \& Herrmann 2006). A região da Serra Negra integra o corredor sudeste do Complexo da Mantiqueira, considerada uma região prioritária para a conservação da biodiversidade de Minas Gerais, devido à elevada riqueza e grau de endemismo de espécies da sua fauna e flora (Drummond et al. 2005). Estudos florísticos na Serra Negra comprovaram uma elevada diversidade e grande taxa de endemismos, reunindo mais de 1.030 espécies de fanerógamas (Salimena et al. 2013) e 210 espécies de pteridófitas (Souza et al. 2012), como vem sendo relatado nos trabalhos de Menini Neto et al. (2009), Abreu \& Menini Neto (2010), Abreu et al. (2011), Feliciano \& Salimena (2011), Valente et al. (2011), Blaser et al. (2012), Matozinhos \& Konno (2011a), Dutra et al. (2012) e Oliveira et al. (2014), além de registros de novas espécies (Batista et al. 2008; Assis \& Melo-Silva 2010; Matozinhos \& Konno 2011b).

Os trabalhos que vem sendo desenvolvidos ao longo de mais de uma década para conhecimento da flora local, subsidiaram a proposta em andamento, para a criação de uma unidade de conservação estadual nesta região, a fim de proteger a biodiversidade da Serra Negra, que conta com apenas três RPPNs em uma área de aproximadamente 10000 hectares (Souza et al. 2012). Como parte do projeto "Flora da Serra Negra" desenvolvido pela Universidade Federal de Juiz de Fora, este trabalho tem como objetivo apresentar o tratamento taxonômico da família Campanulaceae na Serra Negra, contribuindo para o conhecimento e conservação da flora da Serra da Mantiqueira e do estado de Minas Gerais.

\section{Material e Métodos}

A Serra Negra está localizada no Complexo da Mantiqueira, ao sul da Zona da Mata de Minas Gerais (21'58'24'S e 4353'15'W), incluindo parte dos municípios de Lima Duarte, Santa Bárbara do Monte Verde, Rio Preto e Olaria. Apresenta altitudes que variam entre 900 e 1.698 m, clima subtropical de altitude, com inverno seco e verão ameno, classificado como tipo Cwb (Köppen) e precipitação média anual de $1.886 \mathrm{~mm}$ (Valente et al. 2011; Menini Neto et al. 2009).

A vegetação natural da Serra insere-se no Domínio da Floresta Atlântica, sendo composta por campos rupestres e diferentes formações florestais como descritos em Salimena et al. (2013). O levantamento florístico da Serra Negra foi iniciado em 2003, pelo Departamento de Botânica da Universidade Federal de Juiz de Fora, cuja coleção encontra-se depositada no Herbário CESJ. Todos os acrônimos seguem Thiers (continuamente atualizado). A terminologia morfológica está de acordo com Radford et al. (1974) e a descrição dos tricomas segue Harris \& Harris (2001). O "Material examinado" refere-se à coleção da Serra Negra, enquanto o "Material adicional examinado" está representado por coleções de diferentes procedências, utilizadas para complementação das descrições morfológicas ou como referência importante para a distribuição geográfica.

\section{Resultados e Discussão}

A família Campanulaceae está representada na Serra Negra por três gêneros e dez espécies: Centropogon cornutus (L.) Druce, Lobelia exaltata Pohl, Lobelia hilaireana (Kanitz) E.Wimm, Lobelia fistulosa Vell., Lobelia thapsoidea Schott, Siphocampylus longipedunculatus Pohl, Siphocampylus macropodus (Thunb.) G.Don, Siphocampylus nitidus Pohl, Siphocampylus psilophyllus Pohl e Siphocampylus aff. fluminensis (Vell.) E.Wimm.

Entre as espécies encontradas na Serra Negra, apenas $C$. cornutus não é endêmica do Brasil (BGF 2015), ocorrendo do Panamá à Bolívia, Antilhas, Suriname e apresentando ampla distribuição no território brasileiro. Em contrapartida, L. hilaireana e $S$. nitidus são espécies restritas ao estado de Minas Gerais (BGF 2015). Em comparação aos outros estudos da família Campanulaceae para Minas Gerais, a riqueza de espécies na Serra Negra foi próxima da encontrada para a Serra do Cipó (11 espécies, Godoy 1992) e muito maior que para 
Grão Mogol, onde apenas C. cornutus foi relatada (Godoy 2003b). Considerando a comparação com a Flora da Serra do Cipó, apenas L. fistulosa e $S$. nitidus são comuns às duas floras. Destaca-se a ocorrência de Siphocampylus psilophyllus na Serra Negra, que apesar de ser citada para os estados de Minas Gerais e Rio de Janeiro, apresentava registros muito antigos, o último datado de 1932, sendo reencontrada na Serra Negra em coletas do ano de 2004, e mais recentemente em Cambuci, RJ. Foi encontrada uma espécie do gênero Syphocampylus, muito próxima morfologicamente à $S$. fluminensis (Vell.) E.Wimm., que entretanto apresenta flores amarelas, característica não encontrada neste táxon. Dessa forma esta espécie foi incluída como $S$. aff. fluminensis aguardando estudos mais acurados a fim de se estabelecer sua identidade. Tanto $S$. psilophyllus como S. aff. fluminensis são raras, têm ocorrência pontual na Serra Negra, em uma única localidade, em área não protegida, em borda de mata.

\section{Chave para identificação das espécies de Campanulaceae da Serra Negra, Minas Gerais}

1. Tubo da corola fendido longitudinalmente com os 2 lobos superiores disjuntos até a base.................2

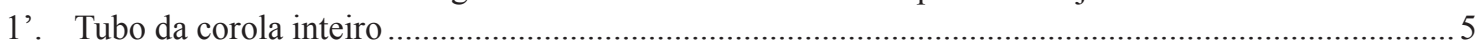

2. Flores com corola alva ou creme-esverdeada ..............................................2.1. Lobelia exaltata

2'. Flores com corola rosa a lilás

3. Ervas com látex amarelo; caule, pedicelo e hipanto glabros; brácteas glabras, lanceoladas..

2.3. Lobelia hilaireana

3'. Ervas com látex branco; caule, pedicelo e hipanto pilosos; brácteas pilosas, ovais, lineares a

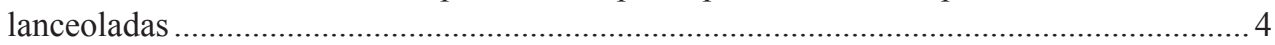

4. Brácteas ovais; bractéolas ausentes; folha com dentículos castanhos ou arroxeados.....

2.2. Lobelia fistulosa

4'. Brácteas lineares a lanceoladas; bractéolas presentes; folhas com dentículos alvos ......

2.4. Lobelia thapsoidea

5. Corola rosa magenta; anteras inferiores terminadas em apêndice cartilaginoso triangular; fruto bacoide ................................................ 1. Centropogon cornutus

5'. Corola amarela ou vermelha; anteras inferiores piloso-peniceladas; fruto cápsula

6. Folhas verticiladas, raro alternas ou opostas na parte inferior do ramo ......... 7

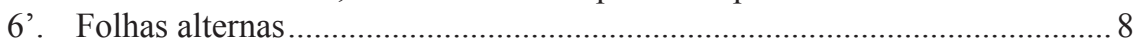

7. Lâmina oval-lanceolada a estreito-elíptica, margem inteira, raro denticulada; corola vermelha com lobos verdes.

7'. Lâmina oval, margem fimbriada;

3.5. Siphocampylus psilophyllus

3.1. Siphocampylus aff. fluminensis

8. Lâmina elíptica, estreito-elíptica a oblanceolada, hipanto deprimidogloboso ..................................... 3.3. Siphocampylus macropodus

8'. Lâmina oval a triangular; hipanto hemisférico ou obcônico..........9

9. Lâmina triangular, membranácea, face adaxial hirsuta; hipanto obcônico; tubo da corola totalmente vermelho

3.2. Siphocampylus longipedunculatus

9'. Lâmina oval, coriácea, face adaxial glabra, hipanto hemisférico; tubo da corola vermelho com lobos amarelos.

3.4. Siphocampylus nitidus

1. Centropogon cornutus (L.) Druce, Bot. Exch. Club Soc. Brit. Isles 3: 416. 1914.

Fig. 1a-f

Erva fistulosa ca. 1,5 m alt.; caule cilíndrico, estriado, lanuginoso, 3-4 mm diâm. Folhas com pecíolo 4-10 mm compr., glabro; lâmina oblonga à estreito-elíptica, 3,2-20,2 × 1,7-6,5 cm, glabra, brilhante, membranácea, presença de papilas nas nervuras da face abaxial, ápice atenuado a obtuso, base atenuada, assimétrica, geralmente prolongase pelo pecíolo em pequena ala, margem inteira 

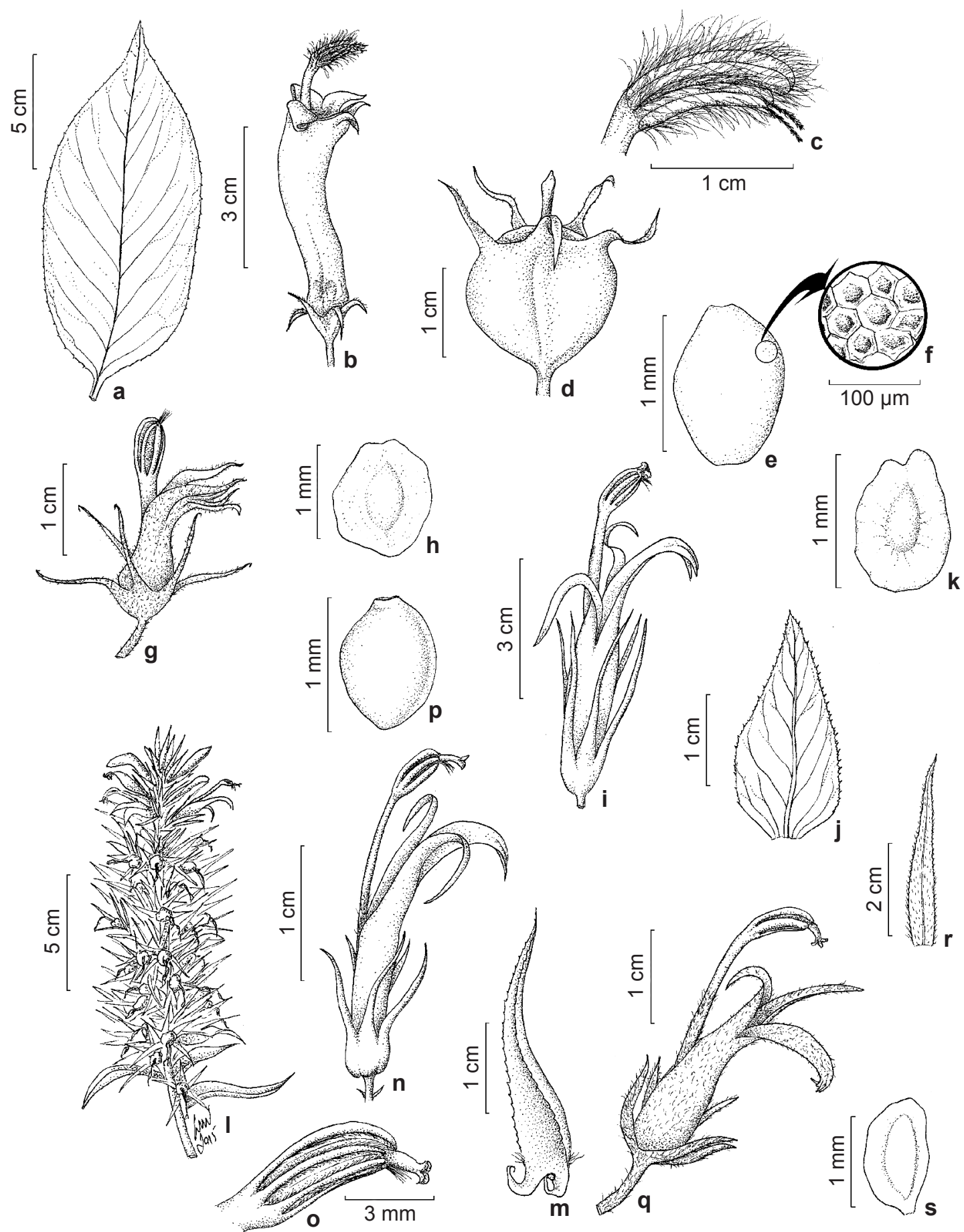

Figura 1 - a-f. Centropogon cornutus - a. folha; b. detalhe da flor; c. detalhes das anteras; d. detalhe do fruto; e. semente; f. detalhe da ornamentação da semente. g-h. Lobelia exaltata - g. detalhe da flor; h. semente. i-k. Lobelia fistulosa - i. detalhe da flor; j. bráctea; k. semente. 1-p. Lobelia hilaireana - 1. inflorescência; m. bráctea; n. detalhe da flor; o. detalhes das anteras; p. semente. q-s. Lobelia thapsoidea - q. detalhe da flor; r. bráctea; s. semente. (a-f. Salimena 3477; g. Salimena 3379; h. Souza 31; i. Ribeiro 80; j-k. Salimena 2634; 1-p. Salimena 2393; q-s. Salimena 3484).

Figure 1 - a-f. Centropogon cornutus - a. leaf; b. detail of flower; c. detail of anthers; d. detail of fruit; e. seed; f. seed ornamentation detail. g-h. Lobelia exaltata - g. detail of flower; h. seed. i-k. Lobelia fistulosa - i. detail of flower; j. bract; k. seed. 1-p. Lobelia hilaireana - 1. inflorescence; m. bract; $\mathrm{n}$. detail of flower; o. detail of anthers; p. seed. q-s. Lobelia thapsoidea - q. detail of flower; r. bract; s. seed. (a-f. Salimena 3477; g. Salimena 3379; h. Souza 31; i. Ribeiro 80; j-k. Salimena 2634; 1-p. Salimena 2393; q-s. Salimena 3484). 
à crenada, denticulada, dentículos alvos. Flores isoladas, axilares, pedicelo sigmóide-ascendente, lanuginoso, 2,1-6,5 cm compr., 2-bracteolado na base, bractéolas lineares, glabras; hipanto globoso, 4-6 × 6-7 mm, lobos do cálice estreito-triangulares ca. 1,1 $\times 0,3 \mathrm{~cm}$, ápices hialinos, raro denticulados, glabros; tubo da corola rosa magenta, inteiro, 4, 1-5,5 cm compr., constrito com reentrâncias na base (5-7 mm larg.), mais amplo próximo aos lobos (9-11 mm larg.), glabro, pubérulo no ápice; tubo de filetes ca. $5,3 \mathrm{~cm}$ compr., glabro; anteras cobertas por tricomas longos, 2 inferiores ca. $6 \mathrm{~mm}$ compr., terminadas em apêndice cartilaginoso triangular, 3 superiores ca. 8 mm compr. Fruto bacóide, mais ou menos carnoso, 11-13 × 13-15 mm, ca. 2/3 livre. Sementes ca. $1 \times$ $0,5 \mathrm{~mm}$, castanhas, foveoladas.

Material examinado: Rio Preto, Vila do Funil, Estrada da Fazenda Santa Clara, 29.IV.2012, fl. e fr., F.R.G. Salimena 3477 (CESJ).

Material adicional examinado: BRASIL. BAHIA: Ubaitaba, 21.IV.1991, fl., R.P. Lyra-Lemos 1873 \& G.L. Esteves (SPF, SPFE). ESPÍRITO SANTO: Fradinhos, Morro da TV, 3.VII.1994, fl, Behar (SPF 178554). MATO GROSSO DO SUL: Novo Mundo, Parque Estadual Cristalino, Olho da Xuxa, 27.I.2008, fl, D.C. Zappi et al. 870 (SPF). SÃO PAULO: Salesópolis, Estação Biológica de Boracéia. 31.III.2000, fl, S.A.P. Godoy et al. 2041 (SPFR).

$\mathrm{O}$ gênero Centropogon compreende cerca de 215 espécies, com distribuição do México ao Brasil, cujo centro de dispersão é a região andina da Colômbia (Lammers 2007). A única espécie com ocorrência no Brasil é C. cornutus, porém, não é endêmica do país, sendo de ampla distribuição do Panamá à Bolívia, Antilhas, Suriname e Brasil (Godoy 2003a, b; BGF 2015). No território nacional, a espécie tem registros para o Amazonas, Acre, Ceará, Bahia, Goiás, Mato Grosso do Sul, Minas Gerais, Rio de Janeiro e São Paulo (BGF 2015). $\mathrm{Na}$ Serra Negra é encontrada em ambientes úmidos e sombreados, com flores de fevereiro a junho. É uma espécie característica pela coloração rosa magenta de suas flores e anteras cobertas por longos tricomas. Comumente confundida com espécies do gênero Siphocampylus, distingue-se principalmente pelos frutos do tipo bacoide e pelo tamanho e posicionamento dos lobos da corola, que são menores em C. cornutus, posicionados 2:3, em Siphocampylus posicionados dois superiores, dois laterais e o inferior ocupa posição mediana.

2.1. Lobelia exaltata Pohl., Pl. Bras. Incon. Descr. 2: 101. tab. 166. 1831.

Fig. 1g-h

Erva fistulosa 1-4 m alt.; látex abundante, branco; caule glabro, 0,9-1,9 cm diâm. Folhas lanceoladas, 1,6-25 × 0,7-2,5 cm, glabras, cartáceas, margem hialina, dentículos desiguais, castanhos. Inflorescência 9,2-32 cm compr.; bráctea lanceolada, 8-21 × 1-4 mm, hirsuta, margem hialina, ciliada. Flores com pedicelo sigmóide-ascendente, 4-9 mm compr., hirsuto; bractéolas ausentes; hipanto 2-3,5 × 3-4 mm, lobos do cálice $9-10 \times 1-4 \mathrm{~mm}$, hirsutos; corola alva ou creme-esverdeada, tubo ca. 7 mm compr., lobos superiores 10-12 mm compr., glabros internamente, lobos inferiores 9-10 mm compr., hirsutos internamente, ambos hirsutos externamente; tubo de filetes ca. $18 \mathrm{~mm}$ compr., hirsuto; anteras negras, raro irregularmente pilosas no ápice, superiores ca. $5 \mathrm{~mm}$ compr., inferiores ca. $4 \mathrm{~mm}$ compr. Cápsulas 10-12 $\times 7-8$ $\mathrm{mm}, 1 / 2$ livres. Sementes amplamente aladas, ca. $1-1,25 \times 0,75-1 \mathrm{~mm}$, ala proporcional ao núcleo seminífero.

Material Examinado: Rio Preto, Serra Negra, Serra da Caveira D’Anta, Fazenda da Tiririca, 23.II.2004, fl. e fr., K. Antunes et al. 35 (CESJ); Mata do Cambuí, 27.I.2007, fl., C.N. Matozinhos et al. 304 (CESJ); Lima Duarte, Serra Negra, Fazenda Serra Negra, Trilha para a Cachoeira da Divisa, 29.II.2008, fl., F.R.G. Salimena et al. 2633 (CESJ); Monte Verde de Cima, Estrada para a Cachoeira do Arco-Íris, 25.II.2012, fl. e fr., F.R.G. Salimena \& P.H. Nobre 3379 (CESJ).

Lobelia exaltata é endêmica do Brasil, com ocorrência nos estados de Minas Gerais, São Paulo, Rio de Janeiro, Santa Catarina e Paraná, em ambientes brejosos, margens de cursos de água e capoeiras (Vieira 2003; BGF 2015). Na Serra Negra pode ser encontrada em áreas alagadas, com muita luminosidade e áreas abertas de pastagem, próximas a cursos d'água. Floresce e frutifica em fevereiro. É uma espécie característica pela coloração alva ou creme-esverdeada da corola e suas flores são muito menores em relação às das outras espécies, o que torna L. exaltata bastante distinta dentro do gênero.

2.2. Lobelia fistulosa Vell., Fl. Flumin. Incon. 8: t. 157.1831.

Fig. 1i-k

Erva fistulosa ca. 3,5 m alt.; látex branco; caule hirsuto, 1,8-3 cm diâm. Folhas lanceoladas a oblanceoladas, 6,4-25,5 × 1,3-3,4 cm, hirsutas na face adaxial, glabras na face abaxial, cartáceas, margem hialina, ciliada na base, dentículos desiguais, castanhos ou arroxeados. Inflorescência 32,5-74,3 cm compr.; bráctea oval, 1,7-10,5 × 0,5-2,6 cm, hirsuta, margem hialina, as superiores arroxeadas. Flores com pedicelo ascendente, 9-17 mm compr., hirsuto, com duas pequenas 
alas; bractéolas ausentes; hipanto ca. $3 \times 7 \mathrm{~mm}$, lobos do cálice 15-22 × 2,5-6 mm, hirsutos; corola rosa a lilás, tubo ca. 2,5 cm compr., lobos superiores ca. 1,7 cm compr., lobos inferiores ca. $1,5 \mathrm{~cm}$ compr., hirsutos; tubo de filetes $3,1 \mathrm{~cm}$ compr., hirsuto; anteras negras, superiores ca. 11 mm compr., inferiores ca. $8 \mathrm{~mm}$ compr. Cápsulas 14-21 × 12-13 mm, 2/3 a 1/2 livres. Sementes amplamente aladas, $1,5-2 \times 1-1,5 \mathrm{~mm}$, ala maior que o núcleo seminífero.

Material examinado: Lima Duarte, Serra Negra, Trilha para a Cachoeira da Divisa, 29.II.2008, fl. e fr., F.R.G. Salimena et al. 2634 (CESJ); RPPN Fazenda Serra Negra, 5.IV.2009, fl. e fr., J.H.C. Ribeiro et al. 80 (CESJ); próximo à Cachoeira do Arco-íris, 25.II.2012, fr., F.R.G. Salimena \& P.H. Nobre 3380 (CESJ).

Material adicional examinado: Caratinga, APA Lagoa Silvana, 5.X.2002, fl. e fr., M.O.D. Pivari \& L.G.S. Soares 162 (CESJ).

Lobelia fistulosa é endêmica do Brasil, com ocorrência nos estados de Minas Gerais, São Paulo e Rio de Janeiro, geralmente presente em campos de altitude, floresta estacional semidecidual, brejos ou locais úmidos e ainda em áreas antropizadas, como margens de estradas (Vieira 2003; BGF 2015). Na Serra Negra é encontrada em brejos e em campos abertos. Floresce e frutifica no período entre Janeiro e Março. Os espécimes analisados para Serra Negra diferem das descrições de Vieira (2003) que descreve a presença de bractéolas nesta espécie, mesmo que caducas, entretanto nos espécimes da Serra Negra, estão ausentes. As folhas são descritas por Vieira (2003) como glabras em ambas as faces, mas a análise em microscopia de luz permitiu verificar a presença de tricomas unicelulares, cônicos e muito frágeis na face adaxial, que se perdem durante o processo de herborização, o que pode ser verificado pelas cicatrizes deixadas na lâmina foliar, também observadas em microscopia de luz. O material adicional examinado, proveniente de CaratingaMG, também apresenta muitos tricomas, mas na forma de escamas e na face abaxial, bem diferente dos observados para o material da Serra Negra e ainda não descritos na literatura.

\subsection{Lobelia hilaireana (Kanitz) E.Wimm, Revista} Sudamer. Bot. 2: 106, 1935.

Fig. 11-p

Erva fistulosa 1,7-3 $\mathrm{m}$ alt.; látex amarelado; caule glabro, verde-arroxeado 4-13 mm diâm. Folhas lanceoladas, 3,4-27,2 × 0,5-5,1 cm, glabras, cartáceas, margem hialina, ciliada na base, dentículos desiguais, arroxeados; nervura principal arroxeada. Inflorescência 4-48,5 cm compr.; bráctea lanceolada, 1-13,2 ×0,2-1,9 cm, glabra; margem hialina, ciliada na base. Flores com pedicelo ascendente, 5-9 mm compr., glabro; às vezes com duas pequenas alas; bractéolas, quando presentes, filiformes, na metade do pedicelo, glabras, ciliadas na base; hipanto 2-5 $\times 3-7 \mathrm{~mm}$, lobos do cálice 20-25 × 2-7 mm, glabros; corola rosada a sulferina, tubo 1,9-2,1 cm compr., lobos superiores 1,9-2,2 cm compr., lobos inferiores 1,6-1,8 cm compr., densamente hirsuta internamente, tricomas esparsos externamente; tubo de filetes 2,8-3,2 cm compr., hirsuto no terço basal; anteras negras, ciliadas ao longo do tubo, superiores ca. $8 \mathrm{~mm}$ compr., inferiores ca. $6 \mathrm{~mm}$ compr. Cápsulas 13-18 × 10-13 mm, 1/3 livres. Sementes com pequena ala em um dos lados, ca. $0,75 \times 0,5 \mathrm{~mm}$.

Material examinado: Rio Preto, Serra Negra, Serra da Caveira D'anta, Faz. da Tiririca, 23.II.2004, fl. e fr., K. Antunes et al. 25 (CESJ); Trilha para o Ninho da Égua, 22.IV.2005, fr., C.N. Matozinhos \& N.L. Abreu 25 (CESJ); Laje perto do Ninho da Égua, 21.I.2006, fl., T. Mota 04 (CESJ); Santa Bárbara do Monte Verde, Serra Negra, Fazenda Cachoeira Alta, 10.II.2007, fl. e fr., F.R.G. Salimena \& P.H. Nobre 2393 (CESJ); Rio Preto, Serra Negra, Afloramento do Ninho da Égua, 1.IV.2012, fl., fr., L. Menini Neto et al. 1029 (CESJ).

Lobelia hilaireana é endêmica do Brasil, com ocorrência restrita no estado de Minas Gerais (BGF 2015). Na Serra Negra pode ser encontrada em áreas de campo rupestre e pastagens. Floresce e frutifica entre janeiro e fevereiro. É uma espécie característica pela presença de látex amarelo, ramos verde-arroxeados e folhas com nervura principal arroxeada, presença de bractéolas na região mediana do pedicelo e sementes com uma pequena ala unilateral. L. hilaireana figura no Livro Vermelho da Flora do Brasil (Martinelli \& Moraes 2013), como espécie ameaçada, principalmente por ocorrer em regiões que sofrem com a retirada da vegetação natural para o estabelecimento de áreas para agricultura e pastagem.

2.4. Lobelia thapsoidea Schott in Pohl, Pl. Bras. Icon. Descr. 2. 102. t. 167. $1831 . \quad$ Fig. 1q-s Erva fistulosa ca. 1,8 m de altura; látex branco; caule piloso, ca. 1,3 cm diâm. Folhas lanceoladas $18,2-27 \times 3,1-5,7 \mathrm{~cm}$, pilosas, membranáceas, margem ciliada, dentículos alvos. Inflorescência ca. $62 \mathrm{~cm}$ compr.; bráctea linear a lanceolada, 2,9-7 ×0,3-1,6 cm, pilosa, margem hialina, ciliada, dentículos alvos. Flores com pedicelo sigmoide-ascendente, 1,4-1,7 cm compr., piloso; bractéolas filiformes, basais, 
pilosas, ciliadas; hipanto ca. $5 \times 9 \mathrm{~mm}$, lobos do cálice ca. $2 \times 0,5 \mathrm{~cm}$, pilosos; corola lilás, tubo ca. 3,1 cm compr., lobos superiores ca. 2,9 cm compr., lobos inferiores ca. $2,3 \mathrm{~cm}$ compr., pilosa; tubo de filetes 3,6-4 cm compr., piloso no terço basal; anteras negras, ciliadas no ápice, 3 superiores ca. $4 \mathrm{~mm}$ compr., 2 inferiores ca. 2 mm compr. Cápsulas 1,0-1,2 × 0,8-1,3 cm, 1/2 livres. Sementes aladas, ca. $0,75 \times 0,5 \mathrm{~mm}$, ala menor que o núcleo seminífero.

Material examinado: Lima Duarte, Serra Negra, Estrada para Santa Bárbara do Monte Verde, Monte Verde de Cima, 29.IV.2012, fl. e fr., F.R.G. Salimena et al.3484 (CESJ).

Lobelia thapsoidea é endêmica do Brasil, com distribuição restrita à região Sudeste $(\mathrm{BFG}$ 2015). Na Serra Negra está presente em barrancos, à beira de estradas. Floresce o ano inteiro, com predominância nos meses de Maio e Junho. Pode ser confundida com L. hilaireana, pela coloração e tamanho das flores e inflorescência, porém $L$. thapsoidea possui anteras ciliadas apenas no ápice, enquanto as anteras de $L$. hilaireana são ciliadas ao longo de todo o tubo de filetes. Além disso, L. thapsoidea possui folhas membranáceas, dentículos alvos, bractéolas basais e sementes aladas, características que a difere de $L$. hilaireana, espécie que que possui uma marcante nervura principal da lâmina foliar arroxeada.

\subsection{Siphocampylus aff. fluminensis (Vell.)} E.Wimm, Repert. Spec. Nov. Regni Veg. 22: 210. 1926.

Fig. $2 \mathrm{a}-\mathrm{d}$

Arbusto 0,5-1,5 m alt.; caule cilíndrico, estriado, lanuginoso, 2-4 $\mathrm{mm}$ diâm. Folhas verticiladas, algumas alternas na parte inferior do ramo; pecíolo 0,5-2,4 cm compr., lanuginoso; lâmina oval, $2-11,3 \times 0,7-6,5 \mathrm{~cm}$, tomentulosa, lanuginosa nas nervuras, membranácea, ápice agudo, base arredondada à atenuada, assimétrica, margem fimbriada, denticulada, dentículos alvos. Flores isoladas, axilares, pedicelo lanuginoso, 3,1-6,8 cm compr., 2-bracteolado na base; hipanto obcônico, $3 \times 5 \mathrm{~mm}$, lanuginoso, lobos do cálice ca. $4 \times 1,5 \mathrm{~mm}$, dentículos alvos; corola totalmente amarela, lanuginosa, tubo $3,7-4,3 \mathrm{~cm}$ compr., constrito na base $2-3 \mathrm{~mm}$ larg., mais amplo próximo aos lobos 6-7,5 $\mathrm{mm}$ larg., lobos 1,1-1,5 cm compr.; tubo de filetes ca. 5 cm compr.; anteras azuladas a acinzentadas, superiores ca. 8 $\mathrm{mm}$ compr., ciliadas no ápice, inferiores ca. $6 \mathrm{~mm}$ compr. Cápsulas obcônicas, 12-19 × 9-11 mm, $1 / 2$ livres. Sementes elipsoides, ca. $0,75 \times 0,25$ $\mathrm{mm}$, castanhas, brilhantes.
Material examinado: Lima Duarte, Serra Negra, Caminho para a Cachoeira, 22.II.2008, fl., F.R.G. Salimena et al. 2609 (CESJ); Estrada para São Sebastião do Monte Verde, 19.IV.2009, fl. e fr., J.H.C. Ribeiro et al. 89 (CESJ); Trilha na área B, 15.VII.2009, fl., J.A. Oliveira et al. 60 (CESJ); Estrada para a Cachoeira do Arco-Íris, 25.II.2012, fl., F.R.G. Salimena \& P.H. Nobre 3374 (CESJ); Lima Duarte, Estrada Monte Verde de Cima, 8.VI.2012, fl. e fr., F.R.G. Salimena et al. 3487 (CESJ).

Esta espécie assemelha-se a Siphocampylus fluminensis (Vell.) E.Wimm. entretanto, não há relatos para corola amarela em $S$. fluminensis e nem registros de ocorrência desta espécie na Serra da Mantiqueira ou em Minas Gerais. S. fluminensis é frequente na Serra do Mar, nos estados de São Paulo, Rio de Janeiro e Paraná (BFG 2015). Portanto, considerando-se as diferenças morfológicas e a distribuição geográfica, optouse por apresentar como S. aff. fluminensis no aguardo do incremento de análises genômicas em andamento, para uma definição segura do táxon. Na Serra Negra é encontrada em locais úmidos e sombreados em borda e interior de mata, encontrada em floração nos meses de fevereiro, abril, junho e julho.

3.2. Siphocampylus longipedunculatus Pohl, Pl. Bras. Icon. Descr. 2: 109, t. 172. 1831.

Fig. 2e-f

Arbusto escandente, 0,5-1 m alt.; caule cilíndrico, estriado, hirsuto, 2-3 mm diâm. Folhas alternas; pecíolo 0,7-1,3 $\mathrm{mm}$ compr., hirsuto; lâmina triangular, 5,9-10,1 × 1,5-3 cm, hirsuta, membranácea, ápice agudo, base arredondada a cordada, margem denticulada, dentículos alvos. Flores isoladas, axilares, pedicelo pubérulo, 7,3-10 cm compr; bractéolas ausentes; hipanto obcônico, ca. $6 \times 4 \mathrm{~mm}$, pubérulo, tricomas curtos, lobos do cálice ca. $4 \times 1 \mathrm{~mm}$; corola totalmente vermelha, hirsuta, tubo 3,6-3,9 cm compr., constrito na base ca. $3 \mathrm{~mm}$ larg., mais amplo próximo aos lobos ca. $5 \mathrm{~mm}$ larg., lobos 0,7-1,1 cm compr.; tubo de filetes ca. 4,6 cm compr.; anteras acinzentadas, superiores ca. $6 \mathrm{~mm}$ compr., inferiores ca. $4 \mathrm{~mm}$ compr. Cápsulas obcônicas, $1-1,6 \times$ ca. $0,6 \mathrm{~cm}$. Sementes elipsoides, ca. $0,5 \times 0,25 \mathrm{~mm}$, castanhas, brilhantes, retículofoveoladas.

Material examinado: Rio Preto, Serra Negra, Trilha para a Água Amarela, 29.IX.2012, fl., G.A. Souza, D.R. Gonzaga, L.L. Justino \& M.R.M. Silva 11 (CESJ).

Siphocampylus longipedunculatus é endêmica do Brasil, com registros para Minas Gerais, São Paulo e Rio de Janeiro (BGF 2015). Na 


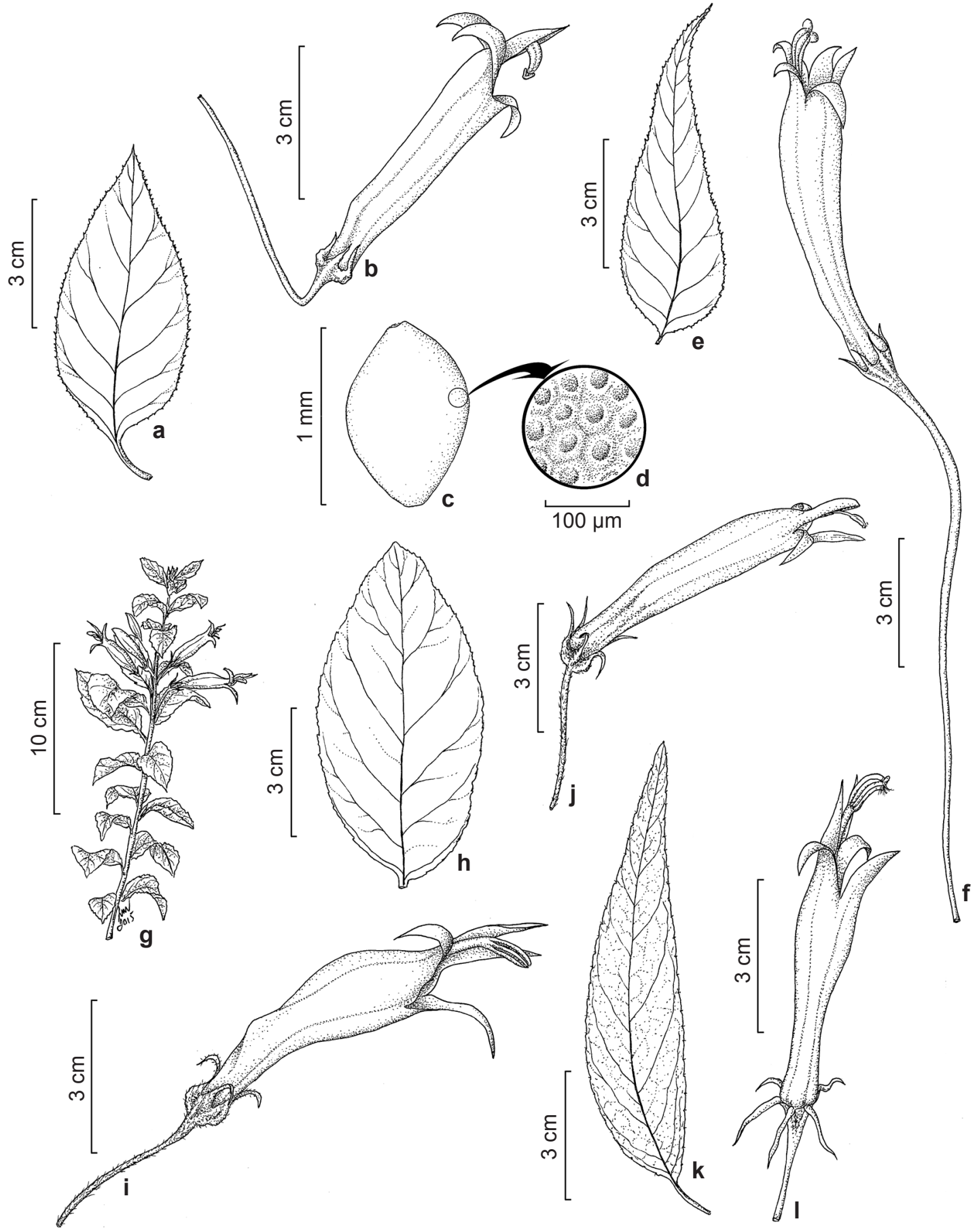

Figura 2 - a-d. Siphocampylus aff. fluminensis - a. folha; b. detalhe da flor; c. semente; d. detalhe da ornamentação da semente. e-f. Siphocampylus longipedunculatus - e. folha; f. detalhe da flor. g-i. Siphocampylus macropodus - g. ápice do ramo com inflorescência; h. folha; i. detalhe da flor. j. Siphocampylus nitidus - detalhe da flor. k-1. Siphocampylus psilophyllus -k. folha; 1. detalhe da flor. (a-d. Salimena 3374; e-f. Souza 29; g-i. Souza 23; j. Salimena 3490; k-1. Assis 962). Figure 2 - a-d. Siphocampylus aff. fluminensis - a. leaf; b. detail of flower; c. seed; d. seed ornamentation detail. e-f. Siphocampylus longipedunculatus - e. leaf; f. detail of flower. g-i. Siphocampylus macropodus - g. apex of branch with inflorescence; h. leaf; i. detail of flower. j. Siphocampylus nitidus - detail of flower. k-1. Siphocampylus psilophyllus - k. leaf; 1. detail of flower. (a-d. Salimena 3374; e-f. Souza 29; g-i. Souza 23; j. Salimena 3490; k-1. Assis 962). 
Serra Negra é encontrada como arbusto escandente na borda da floresta. Os picos de floração vão de abril a setembro. As flores desta espécie estão descritas na literatura (Godoy 2003a) com lobos da corola amarelos ou amarelo-rubros, porém, na Serra Negra, os lobos da corola raramente apresentam algum traço de amarelo. Entre as espécies de Siphocampylus encontradas na Serra Negra, o formato triangular das lâminas foliares e a base arredondada a cordada são características distintivas de $S$. longipedunculatus.

\subsection{Siphocampylus macropodus (Thunb.) G.Don,} Gen. Hist. 3: 702. 1834.

Fig. 2g-i

Arbusto ca. 1,5 m alt.; caule cilíndrico, estriado, lanuginoso, 3-6 mm diâm. Folhas alternas; pecíolo 4-14 mm compr., lanuginoso; lâmina elíptica a estreito-elíptica, 3,2-10,2 $\times 1,1-4,4 \mathrm{~cm}$, tomentulosa na face adaxial, lanuginosa na face abaxial, membranácea à cartácea, ápice agudo, acuminado ou obtuso, base atenuada, assimétrica, margem repando a denteado-denticulada, dentículos alvos. Flores isoladas, axilares, formam aglomerado congesto em direção ao ápice do ramo, pedicelo lanuginoso, 2,2-7,2 cm compr., 2-bracteolado na base; hipanto deprimido-globoso ca. $3 \times 6 \mathrm{~mm}$, lanuginoso, lobos do cálice ca. $2 \times 9 \mathrm{~mm}$, ápice hialino; tubo da corola vermelho, $2,5-3,8 \mathrm{~cm}$ compr., constrito com reentrâncias na base $2-3,5 \mathrm{~mm}$ larg., mais amplo próximo aos lobos 8-10 mm larg., glabro, tricomas esparsos nas nervuras, lobos amarelos a alaranjados, 1-1,5 cm compr.; tubo de filetes ca. $4,3 \mathrm{~cm}$ compr.; anteras amarelo-pálido, superiores ca. $6 \mathrm{~mm}$ compr., inferiores ca. $5 \mathrm{~mm}$ compr. Cápsulas deprimido-globosas, 6-9 × 7-8 mm, 1/2 livres. Sementes elipsoides, ca. 0,5 ×0,25 mm, castanhas, brilhantes.

Material examinado: Lima Duarte, Serra Negra, Estrada para a Cachoeira do Arco-Íris, 25.II.2012, fl. e fr., F.R.G. Salimena \& P.H. Nobre 3385 (CESJ); Divisa Olaria, Sítio do Degredo, 8.VI.2012, fl. e fr., F.R.G. Salimena et al. 3483 (CESJ); Rio Preto, Serra Negra, Fazenda Tiririca, Serra da Caveira D'Anta, 22.II.2004, fl. e fr., $K$. Antunes et al. 07 (CESJ); Próximo à Mata do Benedito, 31.III.2012, fl. e fr., L. Menini Neto et al. 1058 (CESJ); Subida para o Ninho da Égua, 10.VIII.2012, fl., F.R.G. Salimena et al. 3489 (CESJ); Serra do Funil, Fazenda Tiririca, 24.IV.2005, fl., C.N. Matozinhos \& N.L. Abreu 179 (CESJ); Vila do Funil, Gruta do Funil, 29.IV.2012, fl., F.R.G. Salimena 3476 (CESJ).

Siphocampylus macropodus é uma espécie endêmica do Brasil e ocorre na região Sudeste e nos estados de Mato Grosso, Goiás e Paraná
(BGF 2015). Na Serra Negra é encontrada em campos rupestres, em beira de estradas, formando touceiras em campos abertos. Floresce e frutifica de fevereiro a agosto. O látex exala um odor característico, semelhante à cola de nome comercial Araldite. Entre as espécies do gênero encontradas para Serra Negra, S. macropodus apresenta como características distintivas o hipanto deprimido-globoso e folhas membranáceas ou cartáceas, face adaxial tomentulosa, o que facilita sua separação de $S$. nitidus, espécie com a qual é comumente confundida.

3.4. Siphocampylus nitidus Pohl, Pl. Bras. Icon. Descr. 2. 110. t. 174. 1831.

Fig. $2 j$

Arbusto, 0,6-2 m alt.; caule cilíndrico, estriado, ramos superiores lanuginosos, ramos inferiores glabros, ca. 6 mm diâm. Folhas alternas; pecíolo 4-6 mm compr., lanuginoso; lâmina oval a oval-lanceolada, $2-8 \times 0,7-3,1 \mathrm{~cm}$, discolor, coriácea, face adaxial brilhante, glabra com tricomas esparsos na nervura principal, face abaxial lanuginosa, ápice agudo, base arredondada a subcordada, margem ciliada, denticulada, dentículos acastanhados. Flores isoladas, axilares, pedicelo lanuginoso, 1,4-2,5 cm compr.; 2-bracteolado na base; hipanto hemisférico ca. $3 \times 5$ $\mathrm{mm}$, lanuginoso, lobos do cálice ca. $6 \times 1 \mathrm{~mm}$; tubo da corola vermelho, 2,5-3,5 cm compr., constrito na base ca. $2 \mathrm{~mm}$ larg., mais amplo próximo aos lobos ca. $6 \mathrm{~mm}$ larg., lanuginoso, lobos amarelos, 6-9 mm compr., lanuginosos; tubo de filetes ca. 4,1 cm compr., glabro; anteras cinza-claro, ciliadas no ápice, superiores ca. $7 \mathrm{~mm}$ compr., inferiores ca. $5 \mathrm{~mm}$ compr. Cápsula globosa, 3-5 × 7-9 mm, $1 / 3$ livre. Sementes elipsoides, $0,75 \times 0,25 \mathrm{~mm}$, castanho-claras, brilhantes, reticuladas.

Material examinado: Rio Preto, Serra Negra, subida para o Ninho da Égua, 10.VIII.2012, fl. e fr., F.R.G. Salimena et al. 3490 (CESJ); subida para o Ninho da Égua, 2.IX.2012, fl. e fr., D.R. Gonzaga, S.G. Furtado \& L. Menini-Neto 32 (CESJ).

Siphocampylus nitidus é endêmica do Brasil, com ocorrência restrita ao estado de Minas Gerais, encontrada em campos rupestres e cerrado (Godoy 1992; BGF 2015). Na Serra Negra é uma espécie típica dos campos rupestres, floresce e frutifica entre agosto e setembro. É morfologicamente semelhante à $S$. macropodus, porém apresenta como características distintivas principais as folhas coriáceas e brilhantes na face adaxial, dentículos acastanhados e anteras cinza-claras, ciliadas no ápice. 
3.5. Siphocampylus psilophyllus Pohl, Pl. Bras. Icon. Descr. 2: 113. 1831.

Fig. 2k-1

Arbusto ca. 1,5 m alt.; caule cilíndrico, estriado, glabro, 2-3 mm diâm. Folhas verticiladas; pecíolo 0,4-0,9 cm compr., glabro; lâmina ovallanceolada a estreito-elíptica, 5,3-14,4×0,7-3,1 cm, glabra, membranácea, ápice acuminado a cuspidado, base decorrente, assimétrica, margem hialina, inteira, raro denticulada. Flores isoladas, axilares, pedicelo glabro, 2,5-7,9 cm compr., 2-bracteolado na base; hipanto obcônico, ca. $3 \times 4 \mathrm{~mm}$, glabro, lobos do cálice ca. $8 \times 1 \mathrm{~mm}$, margem hialina, ápice hialino; tubo da corola vermelho 3,5-4,5 cm compr., constrito na base $3-4 \mathrm{~mm}$ larg., mais amplo próximo aos lobos 6-7 mm larg., glabro, lobos verdes $0,7-1,1$ cm compr.; tubo estaminal ca. $4,4 \mathrm{~cm}$ compr.; anteras azuladas, superiores ca. $5 \mathrm{~mm}$ compr., inferiores ca. $4 \mathrm{~mm}$ compr. Cápsulas ovoides, 3-5×5-7 mm, 1/2 livres. Sementes não observadas.

Material examinado: Rio Preto, Serra Negra, Fazenda Tiririca, 3.XI.2003, fl., F.R.G. Salimena \& P.H. Nobre 1126 (CESJ); 21.II.2008, fr., F.S. Souza et al. 329 (CESJ); Funil, Serra da Caveira D'Anta, 21.II.2004, fl., L.C.S. Assis et al. 962 (CESJ).

Material adicional examinado: BRASIL. RIO DE JANEIRO: Cambuci, Estrada para Serra Verde, 12.III.2013, fl., M. Nadruz 2780 et al. (RB).

Siphocampylus psilophyllus é endêmica do Brasil, sendo uma espécie pouco representada nas coleções de herbários. Até 1972 eram conhecidas apenas cinco coleções desta espécie, sendo duas coleções tipo, Pohl 984 (K) e Saint-Hilaire B 1-25 (P), ambos espécimes coletados no século XIX, com menção para o Rio de Janeiro, mas sem localidade. A coleção de Saint-Hilaire é tipo para Siphocampylus psilophyllus var. longisepalus, variedade proposta por Wimmer em 1935. O terceiro espécime foi coletado em Natividade, Rio de Janeiro, por Pereira 19 (RB); o quarto e o quinto em Minas Gerais, um por Frambach 107 (NY), em 1932, em Porto Novo, município de Além Paraíba, e o outro por Braga 2421 (RB), em 1972, em Santa Rita de Jacutinga. A partir de então, há quatro novos registros, três para a Serra Negra, apresentados neste trabalho, e um para o município de Cambuci, estado do Rio de Janeiro, coletado por Nadruz 2780 (RB, SPF). Na Serra Negra, a espécie é encontrada apenas na área da Fazenda Tiririca, em borda e interior de floresta ombrófila. Floresce e frutifica de novembro a fevereiro. Analisando as localidades referidas, é possível apontar uma distribuição geográfica restrita em áreas pouco coletadas, representando um indicativo de estar a espécie ameaçada, podendo ser considerada "em perigo", devido à área de ocupação reduzida, severamente fragmentada e atualmente conhecida de apenas cinco localidades.

\section{Agradecimentos}

As autoras agradecem à Fundação de Amparo à Pesquisa do estado de Minas Gerais FAPEMIG e $\mathrm{CNPq}$, o apoio financeiro para realização do presente estudo. A Luiz Menini Neto, as ilustrações e revisão do texto.

\section{Referências}

Abreu, N.L. \& Menini-Neto, L. 2010. As subfamílias Vanilloideae e Orchidoideae (Orchidaceae) em um fragmento da Serra da Mantiqueira, Minas Gerais, Brasil. Boletim de Botânica da Universidade de São Paulo 28: 15-33.

Abreu, N.L.; Menini-Neto, L. \& Konno, T.U.P. 2011. Orchidaceae das Serras Negra e do Funil, Rio Preto, Minas Gerais, e similaridade florística entre formações campestres e florestais do Brasil. Acta Botanica Brasilica 25: 58-70.

Assis, L.C.S. \& Mello-Silva, R. 2010. Three new species of Ocotea (Lauraceae) from the campos rupestres of Brazil. Brittonia 62: 86-94.

Batista, J.A.N.; Mota, R.C.; Abreu, N.L. \& Menini Neto, L. 2008. Habenaria pseudoglaucophylla (Orchidaceae), a new species from Minas Gerais, Brazil. Novon 18: 409-414.

BFG. 2015. Growing knowledge: an overview of seed plant diversity in Brazil. Rodriguésia 66: 1085-1113.

Blaser, J.G.; Salimena, F.R.G. \& Chautems, A. 2012. Gesneriaceae na Serra Negra, Minas Gerais, Brasil. Rodriguésia 63: 705-714.

Costa, C. \& Herrmann, G. 2006. O corredor ecológico da Mantiqueira In: Costa, C.M.R.; Hermann, G.; Pinto, I.A. \& Costa, P.A.M. (eds.). Plano de ação do corredor ecológico da Mantiqueira. Valor Natural, Belo Horizonte. Pp. 13-29.

Drummond, G.M.; Martins, C.S.; Machado, A.B.M.; Sebaio, F.A. \& Antonini, Y. 2005. Biodiversidade em Minas Gerais: um atlas para sua conservação. $2^{\mathrm{a}}$ ed. Fundação Biodiversitas, Belo Horizonte. 222p.

Dutra, S.M.; Salimena, F.R.G. \& Menini-Neto, L. 2012. Annonaceae na Serra Negra, Minas Gerais, Brasil. Rodriguésia 63: 785-793.

Feliciano, E.A. \& Salimena, F.R.G. 2011. Solanaceae na Serra Negra, Rio Preto, Minas Gerais. Rodriguésia 62: 1-22.

Godoy, S.A.P. 1992. Flora da Serra do Cipó, Minas Gerais: Campanulaceae. Boletim de Botânica da Universidade de São Paulo 13: 241-257.

Godoy, S.A.P. 2003a. Campanulaceae. In: Wanderley, M.G.L. et al. (coord.). Flora Fanerogâmica do estado de São Paulo. Instituto de Botânica, São Paulo. Vol. 3, pp. 13-32. 
Godoy, S.A.P. 2003b. Flora de Grão-Mogol, Minas Gerais: Campanulaceae. Boletim de Botânica da Universidade de São Paulo 21: 155-156.

Harris, J.G. \& Harris, M.W. 2001. Plant Identification Terminology: an illustrated glossary. $2^{\text {nd }}$ ed. Spring Lake, Utah. 216p.

Lammers, T.G. 2007. World checklist and bibliography of Campanulaceae. Royal Botanic Gardens, Kew, Richmond. 675p.

Martinelli, G. \& Moraes, M.A. (coord.) 2013. Livro vermelho da flora do Brasil. Andrea Jakobsson, Instituto de Pesquisas do Jardim Botânico do Rio de Janeiro, Rio de Janeiro. 1100p.

Matozinhos, C.N. \& Konno, T.U.P. 2011a. Diversidade taxonômica de Apocynaceae na Serra Negra, MG, Brasil. Hoehnea 38:569-559.

Matozinhos, C.N. \& Konno, T.U.P. 2011b. New Species of Macroditassa (Apocynaceae-Asclepiadoideae) from Minas Gerais, Brazil. Systematic Botany 36: 137-140.

Menini Neto, L.; Matozinhos, C.N.; Abreu, N.L.; Valente, A.S.M.; Antunes, K.; Souza, F.S.; Viana, P.L. \& Salimena, F.R.G. 2009. Flora vascular não-arbórea de uma floresta de grota na Serra da Mantiqueira, Zona da Mata de Minas Gerais, Brasil. Biota Neotrópica 9: 1-14.

Oliveira-Filho, A.T. \& Fontes, M.A.L. 2000. Patterns of floristic differentiation among Atlantic Forests in Southeastern Brazil and the influence of climate. Biotropica 32: 793-810.
Oliveira, J.A.; Salimena, F.R.G. \& Zappi, D. 2014. Rubiaceae da Serra Negra, Minas Gerais, Brasil. Rodriguésia 65: 471-504.

Radford, A.E.; Dickinson, W.C.; Massey, J.R. \& Bell, C.R. 1974.Vascular plant systematics. Harper et Row, Nova York. 891p.

Salimena, F.R.G.; Matozinhos, C.N.; Abreu, N.L.; Ribeiro, J.H.C.; Souza, F.S. \& Menini Neto, L. 2013. Flora fanerogâmica da Serra Negra, Minas Gerais, Brasil. Rodriguésia 64: 311-320.

Stevens, P.F. 2001. Angiosperm Phylogeny Website. Version 9. Disponível em $<$ http://www.mobot. org/MOBOT/research/APweb/>. Acesso em 18 novembro 2015.

Souza, F.S.; Salino, A.; Viana, P.L. \& Salimena, F.R.G. 2012. Pteridófitas da Serra Negra, Minas Gerais, Brasil. Acta Botanica Brasilica 26: 378-390.

Thiers, B. [continuously updated]. Index Herbariorum: A global directory of public herbaria and associated staff. New York BotanicalGarden's Virtual Herbarium. Disponível em $<$ http://sweetgum.nybg. org/ih/>. Acesso em 21 maio 2015.

Valente, A.S.M.; Garcia, P.O.; Salimena, F.R.G. \& Oliveira-Filho, A.T. 2011. Composição, estrutura e similaridade florística da Floresta Atlântica, na Serra Negra, Rio Preto-MG. Rodriguésia 62: 321-340.

Vieira, A.O.S. 2003. Campanulaceae: Lobelia L. In: Wanderley, M.G.L. et al. (coord.). Flora Fanerogâmica do estado de São Paulo. Instituto de Botânica, São Paulo. Vol. 3, pp. 15-52. 